\title{
Comparative study suggests that human bone morphogenetic proteins have no influence on the outcome of operative treatment of aseptic clavicle non-unions
}

\author{
Christian von Rüden ${ }^{1,2} \cdot$ Mario Morgenstern ${ }^{3} \cdot$ Jan Friederichs $^{1} \cdot$ Peter Augat $^{2}$. \\ Simon Hackl ${ }^{1}$ - Alexander Woltmann ${ }^{1} \cdot$ Volker Bühren $^{1} \cdot$ Christian Hierholzer $^{4}$
}

Received: 29 March 2016 / Accepted: 25 July 2016 / Published online: 13 August 2016

(C) The Author(s) 2016. This article is published with open access at Springerlink.com

\begin{abstract}
Purpose The purpose of this study was to evaluate the clinical and radiological outcome following compression plate fixation in combination with autologous bone grafting, with and without additional application of recombinant human bone morphogenetic protein (rhBMP) for treatment of aseptic clavicle non-union.

Methods Between April 2004 and April 2015, 82 patients were treated for clavicle fracture and had developed aseptic clavicle non-union. Seventy-three out of 82 patients were available for follow-up at least one year after revision surgery; among them, 27 women and 46 men, with a median age of 49 (range, 19-86) years. Forty-five patients received compression plate osteosynthesis with autologous bone grafting, and 28 patients obtained compression plate fixation with autologous bone grafting and additional application of rhBMP-2 (3/28 patients) or rhBMP-7 (25/28 patients).

Results Seventy out of 73 non-unions (96\%) healed within 12 months after revision surgery. Functional outcome according to the DASH Outcome Measure (with rhBMP, $33.16 \pm$ 1.17 points; without rhBMP, $30.58 \pm 2.12$ points [mean \pm $\mathrm{SEM}] ; p=0.81$ ), non-union healing ( $p=0.86$ ), time interval
\end{abstract}

Christian von Rüden

christian.vonrueden@bgu-murnau.de

1 Department of Trauma Surgery, Trauma Centre Murnau, Professor Küntscher Str. 8, 82418 Murnau, Germany

2 Institute of Biomechanics, Paracelsus Medical University, Salzburg, Austria

3 Department of Traumatology, University Hospital Basel, Basel, Switzerland

4 Department of Trauma Surgery, University Hospital Zurich, Zurich, Switzerland between revision surgery and bone healing ( $p=0.37)$, as well as post-operative complications, did not demonstrate relevant differences between the treatment groups and were not agedependent.

Discussion Functional and radiological results demonstrate that successful healing of aseptic clavicle non-union is dependent on radical resection of non-union tissue, restoration of length of the shoulder girdle and application of stable locking-plate osteosynthesis in combination with autologous bone grafting, but not dependent on application of additional rhBMP.

Keywords Non-union $\cdot$ Clavicle $\cdot$ Bone morphogenetic protein $\cdot$ rhBMP-2 $\cdot$ rhBMP-7 $\cdot$ Locking compression plate $\cdot$ Bone graft · DASH Outcome Measure

\section{Introduction}

About $5 \%$ of all fractures in adults involve the clavicle, and most of them are located in the middle third of the shaft $[1,2]$. Historically, conservative treatment was recommended for clavicle fractures. However, the majority of these fractures are characterised by displacement of fracture fragments. Recent literature reports an increased risk of symptomatic non-union for comminuted clavicle fractures following conservative as well as surgical treatment including plate osteosynthesis or intramedullary fixation using pins, screws, wires or nails [2]. Approximately one-third of the complications may be avoided by choosing the adequate surgical treatment option [3]. Reliable data are not available, but it is common consensus that symptomatic non-union of clavicle fractures in adults characterised by local tenderness at the nonunion site and pain with shoulder motion is relatively rare [4]. Significant risk factors including drug abuse, diabetes and 
previous surgery of the shoulder have been identified to contribute to the development of non-union or fixation failure [5]. Non-union of clavicle fractures remains a devastating problem in terms of the anatomical configuration and function of the shoulder girdle, and there is still no "gold standard" for operative treatment. Therefore, surgical treatment is complex, technically challenging and may not be cost-effective [6]. Earlier studies demonstrated that treatment of clavicle nonunion using classic surgical techniques of straight or precontoured compression plate osteosynthesis and autologous bone grafting resulted in relatively high clinical and radiological union rates [7]. In symptomatic clavicle non-union or malunion, restoration of the anatomic bone configuration is a mandatory precondition to induce solid osseous healing. Anatomical restoration of length is achieved by performing an osteotomy of the malunited site, followed by application of autologous bone graft and rigid compression plate osteosynthesis. In principal, interposition of autologous bone grafting is a successful tool for the reconstruction of segmental bone loss [8]. Biological augmentation with autologous nonvascularised corticocancellous, cancellous or vascularised grafts, is an important option for successful treatment of non-union, despite increased donor site morbidity $[9,10]$. In this context, only a few case reports have assessed the additional application of recombinant human bone morphogenetic protein (rhBMP) in the upper extremity $[11,12]$.

In this cohort study, the surgical revision concept of open compression plating and autologous bone grafting, with and without additional use of rhBMP, for the treatment of aseptic clavicle non-union was evaluated to determine if osseous healing of aseptic clavicle non-union occurred more frequently, time to bone healing was shorter, and clinical and radiological outcome was better following additional application of rhBMP compared with no rhBMP application.

\section{Patients and methods}

In an 11-year period between April 2004 and April 2015, a retrospective cohort study was performed in a level-1 trauma centre.

Inclusion criteria for the study were as follows:

- Patients over 18 years of age or skeletal maturity at time of surgical revision.

- Open or closed clavicle fracture with initial conservative or operative treatment.

- Development of aseptic clavicle non-union requiring revision procedure a minimum of 4 months after initial fracture treatment.

The exclusion criteria included:
- Patients younger than 18 years.

- Patients with skeletal immaturity or congenital forms of clavicle non-union.

- Septic clavicle non-union with previous or consecutive proof of bacterial growth at the site of interest.

- Non-union following pathological clavicle fracture or caused by previously dystrophic bone.

- Any specific contraindication to the utilisation of rhBMP2 or rhBMP-7, such as allergy.

- Patients unable to give a written informed consent for the study.

- Patients with an increased risk for elective operative treatment according to the American Society of Anesthesiologists (ASA) grade $>3$ [13].

Fractures were classified according to the Allman classification (Table 1) [1]. Fracture healing was defined using the following clinical and radiological outcome parameters: ability to perform weight-bearing without pain, stability at nonunion site, the formation of callus at all four cortices (Heckman's criteria of fracture healing) and the elimination of fracture lines [14]. If fracture healing was not clearly visible on X-ray imaging, a computed-tomography scan was performed to detect radiological non-union. The modern definition of a non-union used in this study is the point of time when normal bone healing processes ceased to the extent that union cannot occur without any additional operative intervention [15].

\section{Standard surgical technique: locking compression plate and autologous bone graft}

In the surgical procedure, the previous surgical approach was used and optionally extended to explore the nonunion site. Implants were removed, and devitalised tissue was extensively debrided until normal viable osseous and soft tissue margins were obtained. Specimens were sent for cultures after removing the initial hardware. Three different diagnostic methods (culture of tissue samples, culture of intraoperative swabs, histopathology of tissue samples) were compared. Biological augmentation involved radical resection of fibrous nonunion tissue and application of autologous bone graft. The material was predominately harvested from the iliac crest, or locally from hypertrophic bone formation at the non-union site. For correct restoration of clavicle length, interposition of autologous bone graft was required. For stabilisation of both the non-union and the autologous bone graft interposition, rigid compression plate osteosynthesis using a long, bridging locking compression plate (LCP) was performed irrespective of the location of clavicle fracture (medial, middle or lateral third). 
Table 1 Patients' data overview

\begin{tabular}{|c|c|c|c|}
\hline Treatment concept & $\begin{array}{l}\text { Compression plating }+ \\
\text { bone grafting } \\
\text { without rhBMP }\end{array}$ & $\begin{array}{l}\text { Compression plating }+ \\
\text { bone grafting } \\
\text { with rhBMP }\end{array}$ & $p$ value \\
\hline Total $n=73$ & 45 & 28 & \\
\hline Cancellous bone grafting $(n)$ & 40 & 19 & \\
\hline Iliac crest bone grafting $(n)$ & 5 & 9 & \\
\hline Male/female $(n)$ & $31 / 14$ & $15 / 13$ & \\
\hline Age (years) & 49 (range, 19-65) & 50 (range, 20-76) & \\
\hline \multicolumn{4}{|l|}{$\begin{array}{l}\text { Index fracture pattern according to the } \\
\text { Allman classification }\end{array}$} \\
\hline - medial third $(n)$ & 4 & 2 & \\
\hline - middle third $(n)$ & 35 & 23 & \\
\hline - lateral third $(n)$ & 6 & 3 & \\
\hline $\begin{array}{l}\text { Range of time between index and } \\
\text { revision surgery (months) }\end{array}$ & 13 (range, 4-42) & 11 (range, 4-50) & \\
\hline \multicolumn{4}{|l|}{ Non-union type } \\
\hline - atrophic/oligotrophic $(n)$ & 44 & 25 & \\
\hline - hypertrophic $(n)$ & 1 & 3 & \\
\hline rhBMP-2 $(n)$ & - & 3 & \\
\hline rhBMP-7 $(n)$ & - & 25 & \\
\hline Range of time to bone healing (months) & $16.6 \pm 1.87$ & $19.2 \pm 2.13$ & $p=0.37^{\mathrm{a}}$ \\
\hline Osseous healing $(n)$ & 43 & 27 & $p=0.86^{\mathrm{b}}$ \\
\hline \multicolumn{4}{|l|}{ DASH Outcome Measure (points) } \\
\hline Mean \pm SEM & $30.58 \pm 1.17$ & $33.16 \pm 2.11$ & $p=0.81^{\mathrm{b}}$ \\
\hline Median & 28.0 & 28.0 & \\
\hline
\end{tabular}

Results are presented as mean \pm standard error of the mean (SEM) and median

${ }^{a} p$ value calculated based on Mann-Whitney test, two-tailed

${ }^{\mathrm{b}} p$ value calculated using unpaired $t$-test, two-tailed

\section{Additional rhBMP application}

Additional application of rhBMPs in this study was conducted using rhBMP-7 (OP-1®; Stryker Biotech, Kalamazoo, MI, USA) from 2004 until April 2013, or rhBMP-2 (InductOs®; Medtronic Biopharma, Heerlen, The Netherlands) starting in May 2013. One complete unit of rhBMP-2 or rhBMP-7 was applied to the non-union area according to manufacturer's instructions in each case. The decision to utilise rhBMP was dependent on the intraoperative assessment and the discretion of the treating orthopaedic trauma surgeon.

\section{Follow-up}

After revision surgery, the identical rehabilitation protocol was conducted with all patients [16]. Follow-up studies were performed at regular intervals, including one week, six weeks, three months and six months, as well as at the most recent office visit to the Department of Orthopaedic Trauma. Followup assessment included thorough physical examination, functional evaluation, and diagnostic radiological studies. The influence of the treatment outcome on patients' mental and physical health status was assessed using the DASH
(Disabilities of the Arm, Shoulder and Hand) Outcome Measure [17]. Outcome measures are presented as median values and quartiles.

\section{Statistical analysis}

Significance between groups was statistically assessed based on Mann-Whitney test. Statistical analysis was performed using IBM SPSS ${ }^{\circledR}$ Statistics for Windows 19.0 (IBM, Armonk, New York, USA). A result was considered to be statistically significant with $p$ value $<0.05$.

\section{Compliance with ethical standards}

All procedures performed in this study involving human participants were in accordance with the bioethical standards of the institutional and national research committee (ID, 2016-019) and with the 1964 Helsinki declaration and its later amendments. Written informed consent was obtained from all individuals participating in the study. Patients were explicitly informed about the "off label" use of rhBMP-2 and rhBMP-7 [18]. 


\section{Results}

An overview of all patients included in this study is displayed in Table 1. Eighty-two patients had been treated with clavicle fracture and had developed aseptic clavicle non-union (Fig. 1). Seventy-three out of 82 patients were available for final follow-up at least one year after revision surgery, among them 27 women and 46 men patients with a median age of 49 (range, 19-86) years. Fifty-three out of 73 patients were referred from an outside hospital, whereas 20 patients were initially treated at our institution. Fourteen patients suffered the clavicle fracture as part of major trauma. Twenty-one patients suffered a car accident, six patients a motor bike accident, 13 patients a bicycle accident, one patient a ski accident, one patient a fall from horseback and another patient a fall from a ladder. Simple falls occurred in 26 patients and a blunt impact in four patients. According to the Allman classification [1], 57 fractures were located in the middle third, ten were in the lateral third and six were in the medial third. One patient had an associated brachial plexus lesion.

The primary treatment for clavicle fracture consisted of conservative treatment in 33 patients, whereas in 40 patients primary operative fracture treatment had been performed. For surgical fracture treatment, 27 one-third tubular plates, six ESIN nails, one ECMES nail (Fig. 5), one Prevot nail, one LCP, two tension band fixation and two Hook plates were used. Hypotrophic and atrophic non-union occurred in 54 and 17 patients, respectively. In two patients, hypertrophic non-union was found.

Operative non-union therapy was performed by two consultants and their teams after a median time period of 15 months following the primary fracture treatment. Forty-five patients received LCP osteosynthesis with autologous bone grafting (42/45 cancellous bone grafting, Fig. 2; 5/45 iliac crest bone grafting, Fig. 3) alone and 28 patients received LCP fixation with autologous bone grafting and additional application of rhBMP-2 (3/28 patients) or rhBMP-7 (25/28 patients).

With our surgical concept, osseous healing of the clavicle non-union (Fig. 4) was achieved in 70 out of 73 patients (96\%) within a time interval of 18 months, on average. In two patients of the cohort group without additional use of rhBMP (non-union site: one $\times$ medial third, one $\times$ lateral third

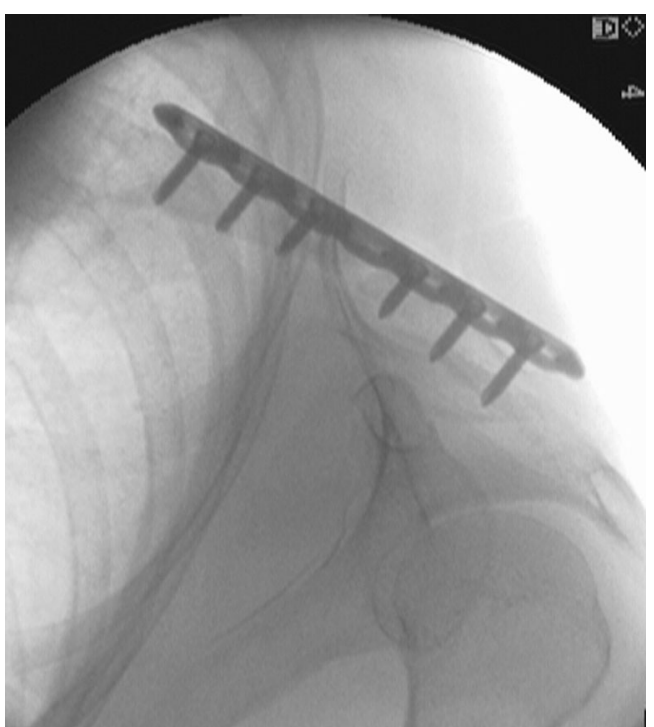

Fig. 2 A 47-year-old woman: insertion of an autologous cancellous bone graft from iliac crest and fixation with a rigid LCP

of the clavicle) and in one patient of the group with additional use of rhBMP (non-union site: middle third of the clavicle), no bone healing was observed $(p=0.86)$. At a median follow-up of 18 months (range, 6-52 months) shoulder flexion averaged $165^{\circ}$ (range, $80-170^{\circ}$ ), $38^{\circ}$ (range, $20-40^{\circ}$ ) for shoulder extension, $77^{\circ}$ (range, $10-90^{\circ}$ ) for abduction, $55^{\circ}$ (range, 20-60 $0^{\circ}$ for adduction, $55^{\circ}$ (range, $20-60^{\circ}$ ) for internal rotation and $55^{\circ}$ (range, $20-60^{\circ}$ ) for external rotation in all included patients. According to the DASH Outcome Measure, there were no significant differences between the cohort groups (with rhBMP, $33.16 \pm 1.17$ points; without rhBMP, $30.58 \pm$ 1.17 points $[$ mean $\pm \mathrm{SEM}$ ]; $p=0.812$; Table 1 ; Fig. 5). Neither the DASH Outcome Measure with rhBMP (Spearman's RankOrder Correlation $r=-0.18 ; p=0.37$ ) or without rhBMP $(r=-0.13 ; p=0.40)$ application nor the complete non-union healing with rhBMP $(r=0.09 ; p=0.65)$ or without rhBMP $(r=0.07 ; p=0.65)$ use was dependent on age. Elective implant removal following complete non-union healing was performed in 33 out of 70 patients. In four patients who had received operative fracture treatment, breakage of the initial revision implant $(3 \times \mathrm{LCP}, 1 \times$ reconstructive plate) occurred. One out of these non-unions healed in the further course,
Fig. 1 A 67-year-old woman after a simple fall on the left clavicle, resulting in a fracture of the middle third. Development of aseptic non-union four months after conservative treatment at an outside institution

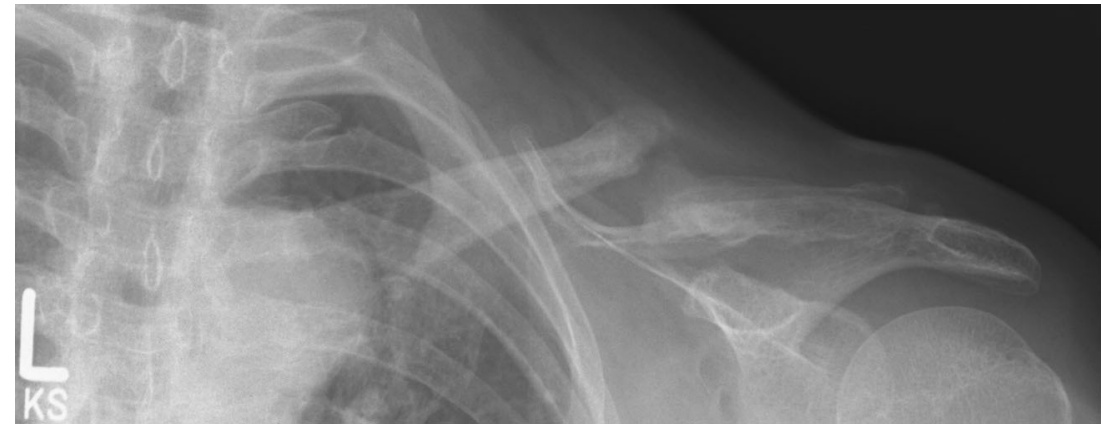




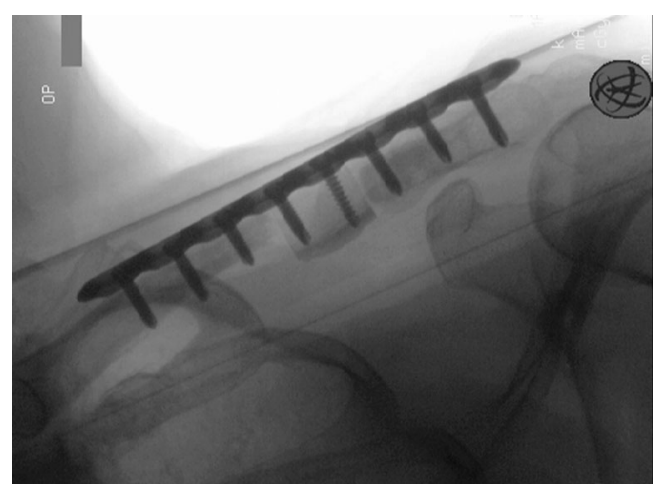

Fig. 3 In the 67-year-old female patient presented in Fig. 1, an autologous tricortical bone graft from the iliac crest was used in combination with rhBMP-7 application and rigid LCP fixation

whereas the remaining three non-unions persisted. In two patients treated with additional use of rhBMP-7, impaired wound healing and inflammation, but no infection, occurred during the osseous consolidation process after revision surgery without any need for further surgical intervention.

\section{Discussion}

Revision rates after operative treatment of clavicle fractures have been reported to reach up to $25 \%$ [19]. Several of these surgical interventions are caused by development of delayed union or non-union at the fracture site. Modern treatment concepts include radical excision of the non-union site, surgical debridement, open reduction and internal fixation using a rigid LCP and application of autologous bone graft, with or without additional administration of rhBMP [20]. Although an increased risk for short-term complications is related to the surgical treatment of clavicle non-union compared with acute fracture treatment [21], autologous bone graft is commonly considered to be the safest and most effective grafting procedure, since it contains a patient's own bone growing cells to enhance osteogenesis and proteins to enhance osteoinduction, while providing a matrix for bone ingrowth (osteoconduction) [8]. In addition, application of autologous bone graft is

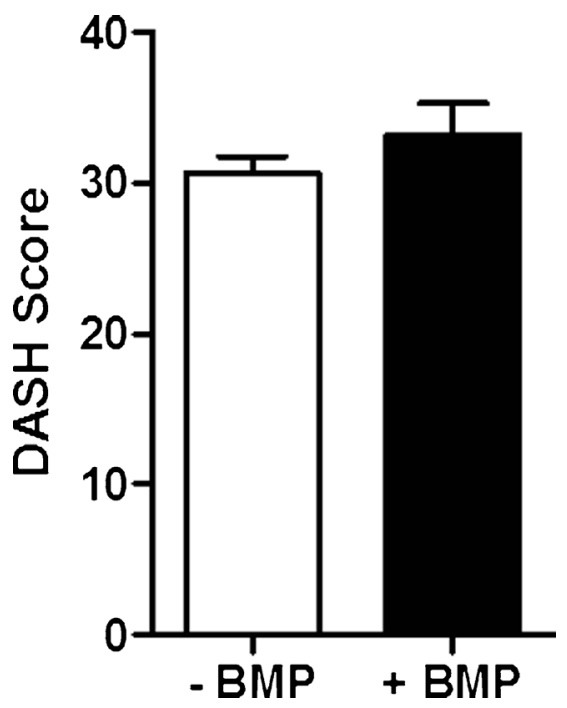

Fig. 5 Functional results according to the DASH Outcome Measure (points) demonstrated no significant difference between both treatment groups ( $p=0.81$; Mann-Whitney test, two-tailed)

performed with the purpose of filling bone defects, and precisely restoring the length and anatomical alignment of the clavicle.

It is critical to achieve high osteosynthetic stability. Thus, bridging plate fixation using an LCP is recommended, and it is advised to insert three or four screws in each fragment, preferably with bicortical screw fixation. Stabilisation using a long, bridging plate requires an extended surgical approach and exposition of the non-union site. Radical resection of interfragmentary fibrous non-union tissue is mandatory. For improvement of local non-union biology, it may also be indicated to perform decortication, resection of avital sclerotic bone and to open a sealed intramedullary canal by using a small-diameter drill.

For promoting bone healing, additional adjuvant treatment concepts using rhBMP have been proposed. Although it remains to be determined if the local environment around an atrophic non-union site is characterised by a deficit of rhBMP or rhBMP receptors, it has been suggested that topical, or local application of rhBMP may be beneficial in accelerating bone healing. Several techniques of rhBMP application
Fig. 4 The 47-year-old female patient presented in Fig. 2: elective metal removal following non-union healing 12 months after revision surgery

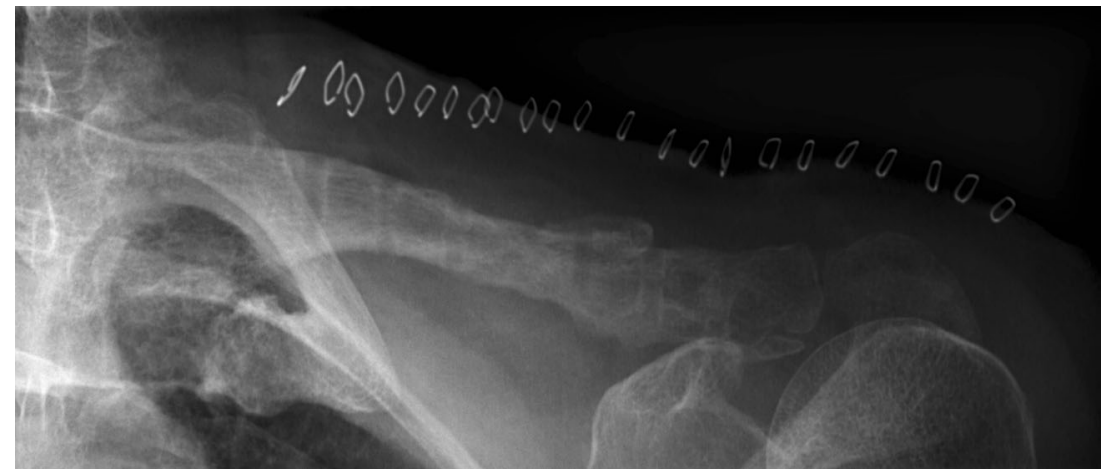


have been utilised including local injection, direct and open application into the non-union site, or insertion of rhBMPcoated implants [22]. RhBMPs promote signalling, chemotaxis, mitosis and differentiation of progenitor cells in the biological process of osteogenesis, and have been shown to accelerate bone healing in both settings of fracture and non-union healing [23]. To our knowledge, this study represents the only trial of aseptic clavicle non-union treated with additional application of both, rhBMP-2 and rhBMP-7, and with at least one year of functional and radiological follow-up. Clinical and radiological results of this study demonstrated complete bone healing in 27 out of 28 patients ( $96 \%$ ) following additional application of rhBMP-2 or rhBMP-7. Risk of impaired wound healing and inflammation, but not infection, following application of rhBMP was found in our study. The phenomenon of transient, local soft-tissue inflammation is a typical adverse effect of rhBMP application. In general, no surgical intervention is required.

A recent study conducted by Morison et al. [24] evaluated the surgical treatment of aseptic long-bone non-union in the upper extremity, and concluded that the application of rhBMP-7 was an effective treatment method with a healing rate of $92 \%$ (22 out of 24 patients), which was a healing rate comparable to the results of our study. In contrast to earlier observations [4, 22], the clinical results of this trial demonstrated good or excellent overall functional results in both treatment groups. Furthermore, despite positive effects on non-union healing in long bones $[4,22]$ and improved quality of life with the use of rhBMP-7 [15], our results demonstrated no significantly increased non-union healing rate or improvement of functional results after additional application of rhBMP. Some studies have also emphasised economic benefits for rhBMP application in non-union treatment by reducing overall treatment time and, thus, treatment costs [22, 25, 26]. Even under economic aspects, the results of our study are not conclusive in order to recommend a general use of rhBMP for the revision treatment of aseptic clavicle non-union, since the rate and time to healing was not significantly different between the two treatment groups. In addition, no relevant correlation between the anatomical localisation of the non-union site at the clavicle, and treatment was found in our trial.

The limitations of this study include the variety of age of patients, initial fracture treatment, and time interval between the fracture and the treatment of the non-union as well as the sequential nature of the two cohort groups. However, the most important outcome assessment of this study was to evaluate the success rate of osseous union using the operative revision technique as described above. The decision to utilise rhBMP was dependent on the intra-operative assessment and the discretion of the treating orthopaedic surgeon, and was not subject to randomised or blinded protocol. Although it is a retrospective investigation, the strengths of the study include the large number of patients managed according to clear inclusion and exclusion criteria, with a consistent standard-treatment protocol in the same hospital by the same group of surgeons with extensive surgical experience in the treatment of clavicle non-union.

In conclusion, functional and radiological results of this study demonstrate that successful bone healing of aseptic clavicle non-union is dependent on a precise surgical technique including radical resection of non-union tissue, restoration of length by interposition of autologous bone graft to prevent shortening of the shoulder girdle and stable locking compression plate fixation, but is independent of the application of additional rhBMP.

Acknowledgments Open access funding provided by Paracelsus Medical University, Austria.

The corresponding author is grateful for Professor Volker Bühren's guidance and support as Medical Director of the Trauma Centre Murnau during recent years.

\section{Compliance with ethical standards}

Conflict of interest The authors declare that they have no conflict of interest.

Open Access This article is distributed under the terms of the Creative Commons Attribution 4.0 International License (http:// creativecommons.org/licenses/by/4.0/), which permits unrestricted use, distribution, and reproduction in any medium, provided you give appropriate credit to the original author(s) and the source, provide a link to the Creative Commons license, and indicate if changes were made.

\section{References}

1. Allman FL Jr (1967) Fractures and ligamentous injuries of the clavicle and its articulation. J Bone Joint Surg Am 49(4):774-784

2. Wu CL, Chang HC, Lu KH (2013) Risk factors for nonunion in 337 displaced midshaft clavicular fractures treated with Knowles pin fixation. Arch Orthop Trauma Surg 133(1):15-22. doi:10.1007 /s00402-012-1631-3

3. Asadollahi S, Hau RC, Page RS, Richardson M, Edwards ER (2016) Complications associated with operative fixation of acute midshaft clavicle fractures. Injury 47(6):1248-1252. doi:10.1016/j. injury.2016.02.005

4. Rosenberg N, Neumann L, Wallace AW (2007) Functional outcome of surgical treatment of symptomatic nonunion and malunion of midshaft clavicle fractures. J Shoulder Elbow Surg 16(5):510 513. doi:10.1016/j.jse.2006.12.002

5. Ban I, Troelsen A (2016) Risk profile of patients developing nonunion of the clavicle and outcome of treatment-analysis of fifty five nonunions in seven hundred and twenty nine consecutive fractures. Int Orthop 40(3):587-593. doi:10.1007/s00264-016-3120-8

6. Dimitriou R, Dahabreh Z, Katsoulis E, Matthews SJ, Branfoot T, Giannoudis PV (2005) Application of recombinant BMP-7 on persistent upper and lower limb non-unions. Injury 36(Suppl 4):S51S59. doi:10.1016/j.injury.2005.10.010

7. Martetschlager F, Gaskill TR, Millett PJ (2013) Management of clavicle nonunion and malunion. J Shoulder Elbow Surg 22(6): 862-868. doi:10.1016/j.jse.2013.01.022 
8. Gómez-Barrena E, Rosset P, Lozano D, Stanovici J, Ermthaller C, Gerbhard F (2015) Bone fracture healing: cell therapy in delayed unions and nonunions. Bone 70:93-101. doi:10.1016/j. bone.2014.07.033

9. Kirchhoff C, Banke IJ, Beirer M, Imhoff AB, Biberthaler P (2013) Operative management of clavicular non-union: Iliac crest bone graft and anatomic locking compression plate. Oper Orthop Traumatol 25(5):483-498. doi:10.1007/s00064-013-0257-0

10. Calkins MS, Burkhalter W, Reyes F (1987) Traumatic segmental bone defects in the upper extremity. Treatment with exposed grafts of corticocancellous bone. J Bone Joint Surg Am 69(1):19-27

11. Calori GM, Tagliabue L, Gala L, d'Imporzano M, Peretti G, Albisetti W (2008) Application of rhBMP-7 and platelet-rich plas$\mathrm{ma}$ in the treatment of long bone non-unions: a prospective randomised clinical study on 120 patients. Injury 39(12):13911402. doi:10.1016/j.injury.2008.08.011

12. Ronga M, Fagetti A, Canton G, Paiusco E, Surace MF, Cherubino P (2013) Clinical applications of growth factors in bone injuries: experience with BMPs. Injury 44(Suppl 1):S34-S39. doi:10.1016 /S0020-1383(13)70008-1

13. Keats AS (1978) The ASA classification of physical status - a recapitulation. Anesthesiology 49:233-236

14. Heckman JD, Ryaby JP, McCabe J, Frey JJ, Kilcoyne RF (1994) Acceleration of tibial fracture-healing by non-invasive, lowintensity pulsed ultrasound. J Bone Joint Surg Am 76:26-34

15. Papanagiotou M, Dailiana $\mathrm{ZH}$, Karachalios T, Varitimidis $\mathrm{S}$, Vlychou M, Hantes M, Malizos KN (2015) RhBMP-7 for the treatment of nonunion of fractures of long bones. Bone Joint J 97-B(7): 997-1003. doi:10.1302/0301-620X.97B7.35089

16. Caspari RB, Beach WR (1993) Arthroscopic anterior shoulder capsulorrhaphy. Sports Med Arthrosc 1(4):237-241

17. Hudak PL, Amadio PC, Bombardier C (1996) Development of an upper extremity outcome measure: the DASH (disabilities of the arm, shoulder and hand) [corrected]. The Upper Extremity Collaborative Group (UECG). Am J Ind Med 29(6):602-608. doi:10.1002 /(SICI)1097-0274(199606)29:6<602::AID-AJIM4>3.0.CO;2-L
18. White AP, Vaccaro AR, Hall JA, Whang PG, Friel BC, McKee MD (2007) Clinical applications of BMP-7/OP-1 in fractures, nonunions and spinal fusion. Int Orthop 31(6):735-741

19. Leroux T, Wasserstein D, Henry P, Khoshbin A, Dwyer T, OgilvieHarris D, Mahomed N, Veillette C (2014) Rate of and risk factors for reoperations after open reduction and internal fixation of midshaft clavicle fractures: a population-based study in Ontario, Canada. J Bone Joint Surg Am 96(13):1119-1125. doi:10.2106 /JBJS.M.00607

20. Giannoudis PV, Einhorn TA, Marsh D (2007) Fracture healing: the diamond concept. Injury 38(Suppl 4):S3-S6

21. McKnight B, Heckmann N, Hill JR, Pannell WC, Mostofi A, Omid R, Hatch GF (2016) Surgical management of midshaft clavicle nonunions is associated with a higher rate of short-term complications compared with acute fractures. J Shoulder Elbow Surg. doi:10.1016/j.jse.2016.01.028

22. Garrison KR, Shemilt I, Donell S, Ryder JJ, Mugford M, Harvey I, Song F, Alt V (2010) Bone morphogenetic protein (BMP) for fracture healing in adults. Cochrane Database Syst Rev 6, CD006950. doi:10.1002/14651858.CD006950.pub2

23. Hausmann M, Ehnert S, Hofmann V, Dobele S, Freude T, Stockle U, Nussler A (2014) Use of bone morphogenetic proteins (BMPs) for the treatment of pseudarthroses - efficiency and therapy failure. Z Orthop Unfall 152(2):144-151. doi:10.1055/s-0034-1368208

24. Morison Z, Vicente M, Schemitsch EH, McKee MD (2016) The treatment of atrophic, recalcitrant long-bone nonunion in the upper extremity with human recombinant bone morphogenetic protein-7 (rhBMP-7) and plate fixation: a retrospective review. Injury 47(2): 356-363. doi:10.1016/j.injury.2015.11.035

25. Dahabreh Z, Dimitriou R, Giannoudis PV (2007) Health economics: a cost analysis of treatment of persistent fracture non-unions using bone morphogenetic protein-7. Injury 38(3):371-377. doi:10.1016/j.injury.2006.08.055

26. Blokhuis TJ, Calori GM, Schmidmaier G (2013) Autograft versus BMPs for the treatment of non-unions: what is the evidence? Injury 44(Suppl 1):S40-S42. doi:10.1016/S0020-1383(13)70009-3 